\title{
The Influencing Factors of Health-Seeking Preference and Community Health Service Utilization Among Patients in Primary Care Reform in Xiamen, China
}

This article was published in the following Dove Press journal:

Patient Preference and Adherence

\author{
Yanbing Zeng' \\ Weiqian $\mathrm{Xu}^{\prime}$ \\ Lele Chen ${ }^{2}$ \\ Fan Chen ${ }^{3}$ \\ Ya Fang'
}

'State Key Laboratory of Molecular Vaccinology and Molecular Diagnostics, Key Laboratory of Health Technology Assessment of Fujian Province University, School of Public Health, Xiamen University, Xiamen, Fujian, People's Republic of China; ${ }^{2}$ School of Social and Behavioral Sciences, Nanjing University, Nanjing, Jiangsu, People's Republic of China; ${ }^{3}$ Xiang'An Hospital of Xiamen University, Xiamen, Fujian, People's Republic of China
Correspondence: Ya Fang

School of Public Health, Xiamen

University, Xiang'an Nan Road, Xiang'an

District, Xiamen, Fujian 36I I02, People's

Republic of China

Tel +86 592-2880636

$\mathrm{Fax}+86592-2880639$

Email fangya@xmu.edu.cn
Introduction: Patients often seek healthcare at general hospitals rather than at community healthcare centres (CHCs) which leads to inefficiency of health services. The primary healthcare reform developed by Xiamen has proven to break through the barriers of hierarchical diagnosis and treatment. The influencing factors of health-seeking behaviours of patients in the Xiamen reform, however, are unclear.

Objective: This study aimed to assess patients' healthcare-seeking preferences and CHCs utilization, and identify influencing factors among patients affected by the Xiamen reform.

Methods: A cross-sectional study composed of 2200 individuals with hypertension or diabetes was conducted in association with Xiamen's reform. The choice of health institutions was used to measure health-seeking preference. The probability and frequency of outpatient service use were used to measure CHC utilization. The social ecological model and two-part model were employed to examine influencing factors.

Results: As high as $72.5 \%$ of the subjects, including those who were under 60 years old, had low education level, with long disease duration, good self-report health and low household income expressed a preference for $\mathrm{CHC}(\mathrm{P}<0.05)$. Also, participants who had good-condition CHCs $\left(\chi^{2}=6.736, \mathrm{P}=0.010\right)$, joined in three-in-one chronic disease management $\left(\chi^{2}=81.615\right.$, $\mathrm{P}<0.01)$ and were insured by medical insurance $\left(\chi^{2}=21.142, \mathrm{P}<0.01\right)$ significantly preferred to visit $\mathrm{CHCs}$ for treatment. In addition, patients who had a preference for $\mathrm{CHC}$ utilized many more CHCs $(\mathrm{P}<0.01)$. Analysis of influencing factors found that education, selfreported health, smoking, household income, condition of the $\mathrm{CHC}$, whether the patient had joined the healthcare reform and whether the patient had medical insurance were important factors affecting health-seeking preference and $\mathrm{CHC}$ utilization $(\mathrm{P}<0.05)$.

Conclusion: The Xiamen healthcare reform made some achievements in improving $\mathrm{CHC}$ utilization. However, certain challenges remain. The government should further strengthen CHCs, deepen and expand healthcare reform, and make efforts to guide reasonable healthcare-seeking behaviour and improve the efficiency of primary health systems.

Keywords: health-seeking preference, community health services utilization, social ecological determinants, chronic diseases, primary care reform

\section{Introduction}

The community health centre, as the cornerstone of a healthcare system, is characterized by providing first-contact, continuous, comprehensive, and coordinated care to individuals as well as families. ${ }^{1}$ The population of a country with a strong 
primary care system has improved health outcomes, particularly reflected in relieving chronic conditions, higher quality of life, and better healthcare system satisfaction in individuals. ${ }^{2}$ In 2008, the World Health Organization (WHO) proposed that primary care be used as an approach to provide effective, fair, and efficient care and that primary care systems be strengthened in all countries. ${ }^{3}$ Many countries, such as the UK, have attempted to use various structures and models to improve primary care and have tried to establish chronic care models to improve primary care for patients with chronic illness. ${ }^{4}$ These models have proved to be effective in improving care and reducing costs. $^{5}$

The healthcare delivery system in China is based on three tiers, namely, primary, secondary and tertiary levels of healthcare. Primary healthcare services are mainly provided by CHCs, which were initially established to maintain public health in the late 1990s and have continued to expand and develop since 2008. ${ }^{6-8}$ However, due to the lack of restrictions in patients' choice of healthcare providers and lower trust in CHCs, most patients tend to seek treatment in hospitals (particularly tertiary hospitals) regardless of disease type and severity. ${ }^{9,10}$ Statistics show that the number of visits to tertiary hospitals was 1.8 times the number of visits to CHCs. ${ }^{11}$ In addition, with the alteration of the disease spectrum, chronic diseases have come to represent a significant threat to human health and development in the current world. Although CHCs have played an increasingly important role in the prevention, treatment and rehabilitation of chronic diseases, patients with chronic diseases prefer to go higher-tier hospitals for routine treatment. ${ }^{12,13}$ This phenomenon in China has resulted in considerable wastage of high-quality medical resources in not only tertiary hospitals but also in unused $\mathrm{CHCs}$ and further aggravated health inequity among residents. ${ }^{14,15}$

To optimize patients' current healthcare-seeking preferences and improve the efficiency of the healthcare system, the Chinese government initiated the "Healthy China 2020 Plan" in 2012 and subsequently implemented a series of pilot projects across the country. ${ }^{16-18}$ In 2014, the National Health and Family Planning Commission (NHFPC) selected the city of Xiamen as the pilot city for hierarchical diagnosis and treatment reform for hypertension and diabetes. ${ }^{19}$ As a municipality in the economically developed southeast coastal area of China, Xiamen has a relatively high level of healthcare and prevalence rate of chronic diseases, and the average life expectancy is above 80 years. ${ }^{19,20}$ Statistics indicated that $13.65 \%$ of residents were aged 60 years and over, and the prevalence of hypertension and diabetes in Xiamen was $16.67 \%$ and $4.61 \%$, respectively. Such serious ageing problems and the shifting of the disease spectrum made hypertension and diabetes rank as the top two issues addressed in all medical visits before 2014 in Xiamen, accounting for more than half of outpatient visits in hospitals. ${ }^{21}$

To address these problems, Xiamen introduced a "three-in-one" team-based care model for chronic disease management in 2015, tested first among patients with hypertension and diabetes. In this model, patients with diabetes or hypertension are assigned to a team of three healthcare workers that consists of a specialist from a general hospital (GH), a general practitioner (GP) from a CHC, and a dedicated health manager. ${ }^{20}$ The specialists play the most significant role in curing patients with severe diseases and training GPs and health managers. The GPs are responsible for managing patients' health through physical examination, prescriptions, and reference to hospitals. Heath managers mainly provide services for disease prevention and control, including regular follow-up and health education, and establish personal health records. Moreover, the government provided financial incentives by increasing fees for chronic disease case management and enhancing the reimbursement mechanism. ${ }^{22}$

It has been reported that the proportion of hypertensive visits to $\mathrm{CHCs}$ increased from $72.6 \%$ to $95.7 \%$ and that diabetic visits increased from $40.7 \%$ to $78.1 \%{ }^{23}$ The three-in-one team-based care model proved to be an effective way to improve the efficiency of the healthcare system. The factors influencing health-seeking preference and CHC utilization in the Xiamen reform, however, are unclear.

There is a strong correlation between health-seeking preference and health service utilization. ${ }^{23-26}$ Existing research has indicated that the health-seeking behaviour of patients is complex and influenced by many factors. However, qualitative studies have examined influential factors of patients' health-seeking behaviour by using the behavioural model of health service use. ${ }^{13,27,28}$ The health promotion field is often criticized for neglecting the environmental underpinnings that impact individuals. ${ }^{29}$ The social ecological model (SEM), as a multi-systems theoretical model, recognizes individuals as embedded within larger social systems and describes the interactive characteristics of individuals and environments. 
Social ecological theory has been proposed as a useful framework for forecasting illness-management behaviours $^{30}$ as well as for community health promotion programmes. ${ }^{31}$ It assumes that complex individual behaviours, such as health-seeking behaviours, are determined by multiple factors and reflect interactions within multiple systems. Building on the SEM, we hypothesized that patients' health-seeking behaviours would be influenced by intrapersonal, interpersonal, institutional, and policy factors. ${ }^{32}$

Employing SEM as a conceptual model, this study aimed to assess patients' healthcare-seeking preference and utilization of CHCs and identify influential factors among patients in the programme of three-in-one teambased care. Our work will generate fresh insight into the study on preferences and utilization of healthcare and provide valid reference for the promotion of primary care in developing countries, such as China.

\section{Materials and Methods Participants}

A cross-sectional study composed of 2200 individuals with hypertension or diabetes was conducted from June to September 2016. Given that the prevalence rate of hypertension or diabetes was $20.8 \%$ in 2014, 2200 patients were selected by a two-stage random sampling method according to the formula: $\mathrm{N}=400^{*}(1-\mathrm{p}) / \mathrm{p}$, where $\mathrm{p}$ is the prevalence rate of diseases, including a $40 \%$ increase to allow for potential non-responders. At the first stage, 5 CHCs (defined as A, B, C, D and E) were selected from 25 CHCs in Xiamen according to economic levels. At the second stage, 440 patients aged over 18 years old were recruited according to treatment records in each CHC. Thereafter, the participants were interviewed by well-trained investigators through face-to-face interviews, and the response rate was $89.6 \%$. Each interviewee was fully aware of the study purpose and of the anonymity and confidentiality of their responses. We checked for completeness of all questionnaires and used EpiData software (version 3.1. EpiData Association, Denmark) for data entry. Double entry was conducted to ensure data accuracy.

\section{Independent Variables Health-Seeking Preference}

Given that China's healthcare delivery system is mainly composed of CHCs (providing primary care) and hospitals (providing secondary/tertiary care), health-seeking preference was measured by asking subjects "In what type of medical institution would you prefer to seek treatment?" (CHC or hospital).

\section{Community Health Services Utilization}

The main services provided by CHCs are outpatient services; therefore, we used the probability and frequencies of outpatient service utilization to express the CHC utilization, which was measured by the questions (1) "Did you see a doctor in the past two months in a CHC?" (2) "How many times did you visit a doctor in the past two months in a CHC?"

\section{Dependent Variables}

According to the multilevel framework proposed by Urie Bronfenbrenner and Mcleroy, ${ }^{32,33}$ dependent variables were categorized into personal characteristics, personal behaviour, interpersonal factors, institutional factors, and public policy. Personal characteristics variables included gender (male/female), age ( $<60$ years old/ $\geq 60$ years old), education (primary school and below, middle school, and high school and above), BMI $\left(<18.5 \mathrm{~kg} / \mathrm{m}^{2}, \quad 18.5-23.9 \mathrm{~kg} / \mathrm{m}^{2}\right.$, 24-27.9 kg/m $\mathrm{m}^{2}$, and $\geq 28 \mathrm{~kg} / \mathrm{m}^{2}$ ), complications (yes/no), duration of diseases (years), and self-reported health (poor, neutral, and good). Personal behaviour variables included smoking (yes/no), drinking (yes/no), and sleep quality (poor, neutral, and good). Interpersonal factors included marriage (married/not married) and monthly household income (<2000 RMB, 2000-3999 RMB, and $\geq 4000$ RMB). Institutional factors included five CHCs, which are named A, B, C, D, and E. Public policy included whether the patient's treatment was managed by the GP team (joined the Xiamen mode) (Yes/no) and whether the patient had medical insurance (uninsured, Urban Employee Basic Medical Insurance (UEBMI), Urban Resident Basic Medical Insurance (URBMI), and others. The New Rural Cooperative Medical System (NRCMS) was not included in this study due to urbanization in Xiamen).

\section{Statistical Analysis}

Descriptive statistics (frequency, percentage, mean (SD)) were used to describe the characteristics of the study sample. Chi-square tests and t-tests were used to analyse the differences in health-seeking preferences and $\mathrm{CHC}$ utilization among patients with different characteristics. Logistic regression analysis was employed to explore factors affecting health-seeking preference. Count data are 
usually characterized by heteroscedasticity, so we constructed a two-part negative binomial model (two-part Negbin) by using the SAS GLIMMIX process to study the influential factors of the probability and frequency of CHC utilization. ${ }^{34-36}$ Data cleaning and analysis were performed by SAS soft, version 9.4 (SAS Institute Inc, Cary, NC, USA).

\section{Results}

\section{Characteristics of the Study Sample}

The total number of collected valid samples was 1972 . A total of $76.2 \%$ were over 60 years old, and $54.4 \%$ were female. A total of $61.5 \%$ had an education attainment of middle school level and below, and $40.6 \%$ of the participants had a BMI larger than $24 \mathrm{~kg} / \mathrm{m}^{2}$. Twenty-six percent lived with complications, and the chronic disease duration was $9.3 \pm 7.2$ years. In total, $17.8 \%, 47.7 \%$, and $32.6 \%$ of the respondents provided self-reported health statuses of poor, neutral and good, respectively. A total of $87.5 \%$ of the respondents were married, and $77.1 \%$ lived in a family with an income of more than 2000 RMB per month. The proportion of respondents was well distributed across CHCs (approximately 20\%). Overall, 50\% of the sample had joined the three-in-one team-based care model, and $92.2 \%$ were covered by medical insurance (Table 1).

\section{Health-Seeking Preference}

Of 1972 respondents, 1429 (72.5\%) individuals reported that they usually sought healthcare in CHCs. As Table 2 shows, in personal characteristics level, respondents under 60 years old were more likely to see a doctor at a $\mathrm{CHC}$ than those over $60\left(78.7 \%\right.$ vs $\left.70.5 \%, \chi^{2}=11.906, \mathrm{P}<0.001\right)$. More than $70 \%$ of participants with middle school education and below were more likely to receive treatment in CHCs, compared with $68.2 \%$ of those with high school education and above $\left(\chi^{2}=12.038, \mathrm{P}=0.002\right)$. Patients with a long disease duration tended to be less likely to seek healthcare in $\mathrm{CHCs}$ than those with a short disease duration $(\mathrm{t}=2.070, \mathrm{P}=0.038)$. A total of $479(74.6 \%)$ individuals with good self-report health preferred to seek treatment in CHCs compared to those with poor health status $\left(\chi^{2}=4.627, \mathrm{P}=0.032\right)$. There was no significant difference in health-seeking preference at the individual behaviour level (smoke, drink and sleep quality). On the interpersonal level, patients with high household income had greater willingness to visit $\mathrm{CHCs}$ than those with low
Table I Characteristics of the Study Sample

\begin{tabular}{|c|c|c|c|}
\hline Variables & & N/Mean & $\% /$ SD \\
\hline Gender & $\begin{array}{l}\text { Male } \\
\text { Female }\end{array}$ & $\begin{array}{l}900 \\
1072\end{array}$ & $\begin{array}{l}45.6 \\
54.4\end{array}$ \\
\hline Age (years) & $\begin{array}{l}<60 \\
\geq 60\end{array}$ & $\begin{array}{l}469 \\
1503\end{array}$ & $\begin{array}{l}23.8 \\
76.2\end{array}$ \\
\hline Education & $\begin{array}{l}\text { Primary school and } \\
\text { below } \\
\text { Middle school } \\
\text { High school and above }\end{array}$ & $\begin{array}{l}695 \\
519 \\
758\end{array}$ & $\begin{array}{l}35.2 \\
26.3 \\
38.4\end{array}$ \\
\hline BMI $\left(\mathrm{kg} / \mathrm{m}^{2}\right)$ & $\begin{array}{l}<18.5 \\
18.5-23.9 \\
24-27.9 \\
\geq 28\end{array}$ & $\begin{array}{l}53 \\
1119 \\
540 \\
260\end{array}$ & $\begin{array}{l}2.7 \\
56.7 \\
27.4 \\
13.2\end{array}$ \\
\hline Complication & $\begin{array}{l}\text { Yes } \\
\text { No }\end{array}$ & $\begin{array}{l}464 \\
1319\end{array}$ & $\begin{array}{l}26.0 \\
74.0\end{array}$ \\
\hline $\begin{array}{l}\text { Duration of Diseases } \\
\text { (years) }\end{array}$ & & 9.3 & 7.2 \\
\hline Self-report health & $\begin{array}{l}\text { Poor } \\
\text { Neutral } \\
\text { Good }\end{array}$ & $\begin{array}{l}390 \\
940 \\
642\end{array}$ & $\begin{array}{l}17.8 \\
47.7 \\
32.6\end{array}$ \\
\hline Marriage & $\begin{array}{l}\text { Married } \\
\text { Unmarried }\end{array}$ & $\begin{array}{l}1725 \\
247\end{array}$ & $\begin{array}{l}87.5 \\
12.5\end{array}$ \\
\hline Monthly household & $<2000$ & 451 & 22.9 \\
\hline Income (RMB) & $\begin{array}{l}2000 \sim 3999 \\
\geq 4000\end{array}$ & $\begin{array}{l}959 \\
562\end{array}$ & $\begin{array}{l}48.6 \\
28.5\end{array}$ \\
\hline $\mathrm{CHCs}$ & $\begin{array}{l}\text { A } \\
B \\
C \\
D \\
E\end{array}$ & $\begin{array}{l}400 \\
398 \\
394 \\
379 \\
401\end{array}$ & $\begin{array}{l}20.3 \\
20.2 \\
20.0 \\
19.2 \\
20.3\end{array}$ \\
\hline $\begin{array}{l}\text { Managed by } \\
\text { GP team }\end{array}$ & $\begin{array}{l}\text { Yes } \\
\text { No }\end{array}$ & $\begin{array}{l}990 \\
982\end{array}$ & $\begin{array}{l}50.2 \\
49.8\end{array}$ \\
\hline Medical insurance & $\begin{array}{l}\text { Uninsured } \\
\text { UEBMI } \\
\text { URBMI } \\
\text { Others }\end{array}$ & $\begin{array}{l}140 \\
801 \\
916 \\
115\end{array}$ & $\begin{array}{l}7.1 \\
40.6 \\
46.5 \\
5.8\end{array}$ \\
\hline
\end{tabular}

household income $\left(\chi^{2}=4.349, \mathrm{P}=0.037\right)$. In terms of the institutional factors, participants had different healthseeking preferences. Specifically, most patients of CHCs $\mathrm{A}, \mathrm{B}, \mathrm{C}$ and $\mathrm{E}$ tended to express a preference for a $\mathrm{CHC}$, while fewer patients of CHC D did so $\left(\chi^{2}=6.736\right.$, $\mathrm{P}=0.010$ ). At the policy level, the preference for the $\mathrm{CHC}$ was much higher in respondents managed by the GP team $(81.5 \%$ VS $63.4 \%, \mathrm{P}<0.001)$ and insured by the UEBMI or URBMI $\left(\chi^{2}=21.142, \mathrm{P}<0.001\right)$. 
Table 2 The Health-Seeking Preference of the Sample

\begin{tabular}{|c|c|c|c|c|c|c|c|}
\hline \multirow[t]{2}{*}{ Variables } & & \multicolumn{2}{|c|}{ Yes $(N=1429)$} & \multicolumn{2}{|c|}{ No $(N=543)$} & \multirow[t]{2}{*}{ Chi-Square } & \multirow[t]{2}{*}{$\mathbf{P}$} \\
\hline & & N/Mean & $\% / \mathbf{S D}$ & N/Mean & $\% / S D$ & & \\
\hline \multicolumn{8}{|l|}{ Personal Characteristics } \\
\hline Gender & $\begin{array}{l}\text { Male } \\
\text { Female }\end{array}$ & $\begin{array}{l}635 \\
794\end{array}$ & $\begin{array}{l}70.6 \\
74.1\end{array}$ & $\begin{array}{l}265 \\
278\end{array}$ & $\begin{array}{l}29.4 \\
25.9\end{array}$ & 3.024 & 0.082 \\
\hline Age (years) & $\begin{array}{l}<60 \\
\geq 60\end{array}$ & $\begin{array}{l}369 \\
1060\end{array}$ & $\begin{array}{l}78.7 \\
70.5\end{array}$ & $\begin{array}{l}100 \\
443\end{array}$ & $\begin{array}{l}21.3 \\
29.5\end{array}$ & 11.906 & 0.000 \\
\hline Education & $\begin{array}{l}\text { Primary school and below } \\
\text { Middle school } \\
\text { High school and above }\end{array}$ & $\begin{array}{l}515 \\
397 \\
517\end{array}$ & $\begin{array}{l}74.1 \\
76.5 \\
68.2\end{array}$ & $\begin{array}{l}180 \\
122 \\
241\end{array}$ & $\begin{array}{l}25.9 \\
23.5 \\
31.8\end{array}$ & 12.038 & 0.002 \\
\hline BMI $\left(\mathrm{kg} / \mathrm{m}^{2}\right)$ & $\begin{array}{l}<18.5 \\
18.5-23.9 \\
24-27.9 \\
\geq 28\end{array}$ & $\begin{array}{l}31 \\
398 \\
191 \\
809\end{array}$ & $\begin{array}{l}58.5 \\
73.1 \\
73.5 \\
72.3\end{array}$ & $\begin{array}{l}22 \\
142 \\
69 \\
310\end{array}$ & $\begin{array}{l}41.5 \\
26.3 \\
26.5 \\
27.7\end{array}$ & 5.745 & 0.125 \\
\hline Complication & $\begin{array}{l}\text { Yes } \\
\text { No }\end{array}$ & $\begin{array}{l}323 \\
964\end{array}$ & $\begin{array}{l}69.6 \\
73.1\end{array}$ & $\begin{array}{l}14 \mid \\
355\end{array}$ & $\begin{array}{l}30.4 \\
26.9\end{array}$ & 2.063 & 0.151 \\
\hline Duration of diseases ${ }^{\mathrm{a}}$ (years) & & 9.09 & 7.1 & 9.84 & 7.3 & 2.070 & 0.038 \\
\hline Self-report health & $\begin{array}{l}\text { Poor } \\
\text { Neutral } \\
\text { Good }\end{array}$ & $\begin{array}{l}266 \\
684 \\
479\end{array}$ & $\begin{array}{l}68.2 \\
72.8 \\
74.6\end{array}$ & $\begin{array}{l}124 \\
256 \\
163\end{array}$ & $\begin{array}{l}31.8 \\
27.2 \\
25.4\end{array}$ & 4.627 & 0.032 \\
\hline \multicolumn{8}{|l|}{ Personal Behaviour } \\
\hline Smoke & $\begin{array}{l}\text { Yes } \\
\text { No }\end{array}$ & $\begin{array}{l}268 \\
1161\end{array}$ & $\begin{array}{l}75.7 \\
71.8\end{array}$ & $\begin{array}{l}86 \\
457\end{array}$ & $\begin{array}{l}24.3 \\
28.2\end{array}$ & 2.272 & 0.132 \\
\hline Drink & $\begin{array}{l}\text { Yes } \\
\text { No }\end{array}$ & $\begin{array}{l}245 \\
1184\end{array}$ & $\begin{array}{l}69.8 \\
73.0\end{array}$ & $\begin{array}{l}106 \\
437\end{array}$ & $\begin{array}{l}30.2 \\
27.0\end{array}$ & 1.518 & 0.218 \\
\hline Sleep quality & $\begin{array}{l}\text { Poor } \\
\text { General } \\
\text { Good }\end{array}$ & $\begin{array}{l}361 \\
469 \\
599\end{array}$ & $\begin{array}{l}72.3 \\
71.3 \\
73.5\end{array}$ & $\begin{array}{l}138 \\
189 \\
216\end{array}$ & $\begin{array}{l}27.7 \\
28.7 \\
26.5\end{array}$ & 0.322 & 0.570 \\
\hline \multicolumn{8}{|l|}{ Interpersonal Levels } \\
\hline Marriage & $\begin{array}{l}\text { Married } \\
\text { Unmarried }\end{array}$ & $\begin{array}{l}1248 \\
181\end{array}$ & $\begin{array}{l}72.4 \\
73.3\end{array}$ & $\begin{array}{l}477 \\
66\end{array}$ & $\begin{array}{l}24.2 \\
26.7\end{array}$ & 0.094 & 0.759 \\
\hline Monthly household income (RMB) & $\begin{array}{l}<2000 \\
2000-3999 \\
\geq 4000\end{array}$ & $\begin{array}{l}310 \\
699 \\
420\end{array}$ & $\begin{array}{l}68.7 \\
72.9 \\
74.7\end{array}$ & $\begin{array}{l}141 \\
260 \\
142\end{array}$ & $\begin{array}{l}31.3 \\
27.1 \\
25.3\end{array}$ & 4.349 & 0.037 \\
\hline \multicolumn{8}{|l|}{ Institutional factors } \\
\hline $\mathrm{CHCs}$ & $\begin{array}{l}\text { A } \\
B \\
C \\
D \\
E\end{array}$ & $\begin{array}{l}292 \\
276 \\
273 \\
312 \\
276\end{array}$ & $\begin{array}{l}73.0 \\
69.4 \\
69.3 \\
82.3 \\
68.8\end{array}$ & $\begin{array}{l}108 \\
122 \\
121 \\
67 \\
125\end{array}$ & $\begin{array}{l}27.0 \\
30.7 \\
30.7 \\
17.7 \\
31.2\end{array}$ & 6.736 & 0.010 \\
\hline \multicolumn{8}{|l|}{ Political Levels } \\
\hline Managed by GP team & $\begin{array}{l}\text { Yes } \\
\text { No }\end{array}$ & $\begin{array}{l}807 \\
622\end{array}$ & $\begin{array}{l}81.5 \\
63.4\end{array}$ & $\begin{array}{l}183 \\
360\end{array}$ & $\begin{array}{l}18.5 \\
36.7\end{array}$ & 81.615 & $<0.001$ \\
\hline
\end{tabular}


Table 2 (Continued).

\begin{tabular}{|c|c|c|c|c|c|c|c|}
\hline \multicolumn{2}{|l|}{ Variables } & \multicolumn{2}{|c|}{ Yes $(\mathrm{N}=1429)$} & \multicolumn{2}{|c|}{ No $(N=543)$} & \multirow[t]{2}{*}{ Chi-Square } & \multirow[t]{2}{*}{$\mathbf{P}$} \\
\hline & & N/Mean & $\% / S D$ & N/Mean & $\% / S D$ & & \\
\hline Medical insurances & $\begin{array}{l}\text { Uninsured } \\
\text { UEBMI } \\
\text { URBMI } \\
\text { Others }\end{array}$ & $\begin{array}{l}84 \\
585 \\
689 \\
71\end{array}$ & $\begin{array}{l}60.0 \\
73.0 \\
75.2 \\
61.7\end{array}$ & $\begin{array}{l}56 \\
216 \\
227 \\
44\end{array}$ & $\begin{array}{l}40.0 \\
27.0 \\
24.8 \\
38.3\end{array}$ & 21.142 & $<0.001$ \\
\hline
\end{tabular}

Note: ${ }^{a}$ t-test was used to compare the duration of diseases between different health-seeking preferences.

\section{The Influencing Factors of Health-Seeking Preference and $\mathrm{CHC}$ Utilization}

In the logistic regression of health-seeking preference, we found that patients with chronic illness who were female, were aged under 60 years old, had a middle school education level and had good self-reported health preferred to seek treatment in CHCs. Cigarette smoking, household income $\geq 4000$, management by GP team and being insured by URBMI increased the preference for CHCs (Table 3).

Putting health-seeking preference as an independent variable in the two-part model of $\mathrm{CHC}$ utilization, we found a strong association between preference for and utilization of CHC. Patients with BMI beyond 28, higher household income, poorer sleep quality, using alcohol or cigarettes, managed by the GP team and insured by UEBMI or URBMI had a higher probability and frequency of using CHC. In addition, having high school education and above, no complications, long duration of disease and good self-reported health significantly reduced the frequency of $\mathrm{CHC}$ utilization. At the institutional level, we found that the $\mathrm{CHC}$ utilization in $\mathrm{CHC} \mathrm{B}$ and $\mathrm{CHC} \mathrm{E}$ was rather low due to the poor-quality medical service and irrational distribution of medical resources (Table 3).

\section{Discussion}

Currently, chronic disease is the leading global health threat and consumes large amounts of medical resources, ${ }^{37}$ especially in China. Statistics indicate that chronic disease treatment accounted for more than $50 \%$ of outpatient visits in tertiary hospitals in Xiamen, with more than $30 \%$ of them for renewing an existing prescription. ${ }^{38}$ According to earlier papers, only approximately $5 \%$ of all patients require treatment by a specialist, while more than $90 \%$ of chronic diseases can potentially be well managed by a GP. ${ }^{39}$ Therefore, there is an urgent need to optimize Chinese patients' current healthcare-seeking preferences to release medical resources in hospitals and improve the efficiency of CHC utilization. As a pilot city for health policy reform, the Xiamen government introduced an innovative reform named the three-inone team-based care model, which changed chronic disease management and redesigned the healthcare system.

In our study, $72.5 \%$ of respondents preferred to seek treatment in CHCs, and those with a health-seeking preference for CHCs had a high probability and frequency of using CHCs in the Xiamen reform. These results mean that the three-in-one team-based care model had an impact on encouraging more appropriate health-seeking behaviour in patients with chronic diseases and more efficient use of CHCs. ${ }^{20,40}$ Then, we adopt an ecological perspective to examine the influencing factors of the health-seeking behaviour regarding CHCs.

\section{Personal Characteristics}

Gender and age are the primary factors influencing patients' preference. Women may prefer to use CHCs for the following two reasons: 1) Women usually live in worse health status than men in China; 2) With the development of $\mathrm{CHCs}$, there are more incentives to seek treatment in community centres than in hospitals. ${ }^{41,42}$ In our study, $70.8 \%$ of women reported poor or neutral health, and the incentive policy allowing patients to buy nearly one month of medicine in a $\mathrm{CHC}$ and other incentives are more attractive to women. ${ }^{23}$ With respect to age, worse health conditions could limit the activities of daily living of the elderly. As a result, elderly individuals are more inclined to seek treatment in hospitals with the help of families when they have serious health problems and require healthcare.

Patients with a high school education and above showed a lower preference for and frequency of using CHCs in the past two months. This is consistent with the fact that the more educated elderly tend to pursue higher quality medical care and techniques in higher-tier hospitals and have lower trust in CHCs. ${ }^{43-45}$ To achieve a higher quality of care for 
Table 3 Influencing Factors of Health-Seeking Preference and CHC Utilization

\begin{tabular}{|c|c|c|c|c|}
\hline \multirow[t]{2}{*}{ Variables } & & \multirow[t]{2}{*}{ ( 1$)$} & \multicolumn{2}{|l|}{ (2) } \\
\hline & & & Probability & Frequency \\
\hline \multicolumn{5}{|l|}{ Patients' preference } \\
\hline CHC (Ref. Hospital) & & - & $0.70 I^{* *}$ & $0.36 I^{* *}$ \\
\hline \multicolumn{5}{|l|}{ Personal Characteristics } \\
\hline Gender (Ref. Female) & Male & $-0.169 *$ & -0.054 & 0.006 \\
\hline Age (years) (Ref.<60) & $\geq 60$ & $-0.227 * *$ & -0.181 & -0.104 \\
\hline \multirow[t]{2}{*}{ Education (Ref. Primary School and below) } & Middle school & $0.244 * *$ & -0.117 & -0.073 \\
\hline & High school and above & $-0.279 * *$ & -0.322 & $-0.225^{*}$ \\
\hline \multirow[t]{3}{*}{ BMI $\left(\mathrm{kg} / \mathrm{m}^{2}\right)$ (Ref. I8.5-23.9) } & $<18.5$ & $-0.48 I^{*}$ & 0.067 & 0.044 \\
\hline & $24 \sim 27.9$ & 0.130 & 0.043 & 0.009 \\
\hline & $\geq 28$ & 0.186 & $0.486 *$ & $0.273^{*}$ \\
\hline Complication (Ref. Yes) & No & 0.011 & -0.249 & $-0.289 * *$ \\
\hline Duration of diseases (years) & & -0.009 & 0.016 & $0.012^{*}$ \\
\hline \multirow[t]{2}{*}{ Self-report health (Ref. Poor) } & Neutral & 0.037 & -0.136 & -0.192 \\
\hline & Good & $0.218^{*}$ & -0.277 & $-0.276^{*}$ \\
\hline \multicolumn{5}{|l|}{ Personal Behaviour } \\
\hline Smoking (Ref. No) & Yes & $0.259 * *$ & $-0.155^{*}$ & $-0.007^{*}$ \\
\hline Drinking (Ref. No) & Yes & -0.082 & $-0.105^{*}$ & $-0.068 *$ \\
\hline \multirow{2}{*}{ Sleep quality (Ref. Poor) } & Neutral & -0.167 & 0.098 & 0.114 \\
\hline & Good & 0.049 & $-0.354 * *$ & $-0.237^{*}$ \\
\hline \multicolumn{5}{|l|}{ Interpersonal Factors } \\
\hline Marriage (Ref. Married) & Others & 0.083 & -0.140 & -0.038 \\
\hline \multirow[t]{2}{*}{ Monthly household income (RMB) $($ Ref. $<2000)$} & 2000-3999 & 0.099 & $0.614^{* *}$ & $0.346 * *$ \\
\hline & $\geq 4000$ & $0.203^{*}$ & $0.662^{* *}$ & $0.430 * *$ \\
\hline \multicolumn{5}{|l|}{ Institutional factors } \\
\hline \multirow[t]{4}{*}{ CHCs (Ref. A) } & B & $-0.306 * *$ & $-0.696 * *$ & $-0.335^{* *}$ \\
\hline & $\mathrm{C}$ & -0.134 & 0.041 & -0.080 \\
\hline & $\mathrm{D}$ & $0.562^{* *}$ & -0.019 & -0.078 \\
\hline & $\mathrm{E}$ & -0.098 & -0.182 & $-0.278^{*}$ \\
\hline \multicolumn{5}{|l|}{ Political Factors } \\
\hline Managed by GP team (Ref. No) & Yes & $0.543 * *$ & $0.336^{*}$ & $0.247^{* *}$ \\
\hline \multirow[t]{3}{*}{ Medical insurance (Ref. Non) } & UEBMI & 0.189 & $0.739 * *$ & $0.648^{* *}$ \\
\hline & URBMI & $0.354 * *$ & $0.614 *$ & $0.524 * *$ \\
\hline & Others & -0.295 & 0.425 & 0.432 \\
\hline
\end{tabular}

Notes: *Significant at 0.05 level, **Significant at 0.01 .

Abbreviations: Column I, factors influencing the patients' preference for treating in CHCs; Column 2, factors influencing the patients' CHS utilization.

patients with different education levels, it is urgent to enhance the quality of CHCs (capacity of health staff, medical environment, and medical techniques). ${ }^{46}$

In this study, health status was found to be the determining factor of $\mathrm{CHC}$ utilization, which is consistent with an earlier paper. ${ }^{47}$ People who were obese, had complications, had a long disease duration or reported poor health usually went to CHCs more frequently. This might be explained by the fact that obesity increases the risk of developing chronic diseases, leading to complications and worse health conditions. Moreover, chronic disease patients need long-term prescriptions. Compared to hospitals, which can prescribe medicine for chronic diseases for only one week at a time, the Xiamen reform allowed $\mathrm{CHCs}$ to extend prescription 
drugs for 4-8 weeks, which greatly increased the convenience of and compliance with chronic disease management for patients. $^{22}$

\section{Individual Behaviour}

Our analysis indicated that smoking, drinking and poor sleep quality slightly increased $\mathrm{CHC}$ utilization. This was mainly because health-risk behaviours may expose the elderly to higher health risks, thereby increasing their demands for healthcare. ${ }^{48}$

\section{Interpersonal Level}

We found that household income significantly impacted health-seeking preferences and $\mathrm{CHC}$ utilization. People with high income tended to visit $\mathrm{CHCs}$ more often, which was different from Tian Shen's result. ${ }^{44}$ Other authors found that low income is linked to unmet needs and poor access to healthcare. ${ }^{49}$ Although the Xiamen reform has subsidized medicine expenses and raised reimbursement rates in $\mathrm{CHCs}$, the health inequalities caused by income disparities remain. The government should make additional efforts to enhance the compensation of medical expenses and eliminate the barriers to accessing healthcare for lowincome populations. 50

\section{Institutional Factors}

Residents from different $\mathrm{CHCs}$ showed different healthseeking preferences and $\mathrm{CHC}$ utilization. In this study, patients from $\mathrm{CHC} \mathrm{B}$ had the lowest preference for, probability of and frequency of $\mathrm{CHC}$ use. We found that the small scale, poor healthcare conditions and heavy traffic of CHC B were the dominant limitations for people using health services. This might explain why healthcare inequity still existed in $\mathrm{CHCs}^{51}$ in Xiamen and is in line with the results of Lin YB. ${ }^{52}$ Previous studies have pointed out that to improve health equality, the scale of the community and its administered population should be considered. ${ }^{53}$ Therefore, the government should concentrate on promoting healthy equality by distributing health resources reasonably and taking advantage of different geographical characteristics.

\section{Public Policy}

Patients managed by the GP team preferred to see doctors in $\mathrm{CHCs}$ and had a higher probability and frequency of $\mathrm{CHC}$ utilization, which suggested that the disease management method by the GP team was an effective way compared to the patients' disease management by themselves. First and foremost, the health managers in the GP teams maintained the continuity and improved the effectiveness of chronic disease management via frequent contacts, health education, health interventions and follow-ups, which substantially enhanced patient compliance. ${ }^{20}$ Second, the increasing drug variety and replacement of obsolete equipment increased the attractiveness and acceptance of $\mathrm{CHCs}$ as the initial point of contact for care.

Furthermore, medical insurance plays a key role in health-seeking preference and could be one of the most important measures towards reducing health inequity. ${ }^{54}$ Compared to the $30 \%$ out-of-pocket percentage in hospitals, the lower out-of-pocket percentage (7\%) required for CHC use by patients managed by the GP team could attract more $\mathrm{CHC}$ utilization. ${ }^{55}$ Therefore, it is necessary to make efforts to extend medical insurance coverage in order to establish primary care-oriented healthcare based on CHCs, with GPs serving as "gatekeepers".

\section{Limitations and Strengths of the Study}

A few limitations, however, remain in this study. First, most of the sampled individuals in our study were over 60 years old, which contributes to potential bias. A possible reason is that the elderly are more likely to have chronic diseases and need more medical service. Another reason is that most participants in the three-in-one chronic disease management programme are elderly. Second, this study focused on two main chronic diseases, hypertension and diabetes, which may weaken the generalizability of our findings. This is because the first stage of the three-in-one chronic disease management programme is specifically aimed at hypertensive and diabetic patients. Third, there was limited analysis of the relationship between influencing factors within the framework of SEM. Such analysis is expected to be considered in future studies.

Despite these limitations, the findings reported here shed new light on health-seeking preferences and the utilization of CHCs. Our study will make several contributions to the current healthcare system. First, our study focused on the major issue of patients crowding into hospitals, which aggravates the inefficiency and difficulty of health resource allocation in the healthcare system in China. Then, we explored the influencing factors of healthseeking behaviour based on SEM, which not only makes up for the deficiencies in prior studies but also provides a new comprehensive perspective to evaluate healthcare 
reform. Last, our results have great reference value for further deepening health reform.

\section{Conclusion}

The implementation of innovative primary care reform in Xiamen has made some achievements in improving $\mathrm{CHC}$ utilization. However, certain challenges remain, such as underutilization of $\mathrm{CHCs}$ among marginalized groups (elderly, poor, uneducated), lower recognition of $\mathrm{CHCs}$ among higher educated populations, and insufficient incentives and coverage of health reform. To guide reasonable healthcare-seeking behaviour and improve the efficiency of primary health systems, the government should further strengthen the primary healthcare system, deepen and expand healthcare reform, make efforts to protect the interest of marginalized populations and eliminate health inequalities.

\section{Abbreviations}

NCDs, non-communicable chronic diseases; CHCs, community health centres; SEM, social ecological model; GP team, general practitioner-centred team; two-part model, two-part negative binomial model; UEBMI, Urban Employee Basic Medical Insurance; URBMI, Urban Resident Basic Medical Insurance; NRCMS, New Rural Cooperative Medical System; USA, the United States of America.

\section{Ethics and Consent Statement}

The study was carried out in conformance with the declaration of Helsinki. Ethical approval was received from the Ethics Committee of Health Care District of Central Finland and the Ethics Committee of the School of Public Health, Xiamen University. All participants in our study completed a participant's informed consent form prior to participation.

\section{Funding}

This work was supported by the National Natural Science Foundation of China (NO. 71874147) and the Project of Natural Science Foundation of Fujian Province (No. 2017J01133). The funders had no role in the study design, data collection and analysis, decision to publish or preparation of the manuscript.

\section{Disclosure}

The authors report no conflicts of interest in this work.

\section{References}

1. Starfield B. Is primary care essential? Lancet. 1994;344 (8930):1129-1133. doi:10.1016/S0140-6736(94)90634-3
2. Shi L, Lee DC, Liang H, et al. Community health centers and primary care access and quality for chronically-ill patients - a case-comparison study of urban Guangdong Province, China. Int $J$ Equity Health. 2015;14(1):1-17. doi:10.1186/s12939-014-0131-1

3. World Health Organization. The World Health Report 2008: primary health care - now more than ever. Geneva, Switzerland: WHO. Available from: https://www.who.int/whr/2008/whr08_en.pdf. Accessed 17 February 172019.

4. Renders CM, Valk GD, Griffin SJ, Wagner EH, Eijk Van JT, Assendelft WJ. Interventions to improve the management of diabetes in primary care, outpatient, and community settings: a systematic review. Diabetes Care. 2001;24(10):1821-1833. doi:10.2337/diacare.24.10.1821

5. Bodenheimer T, Wagner EH, Grumbach K. Improving primary care for patients with chronic illness. JAMA. 2002;288(14):1775-1779. doi:10.1001/jama.288.14.1775

6. Shen Q, Tang L. Patient preferences, concerns, and satisfaction with providers before the Chinese urban health system reform: a social groups analysis. SSRN Electron J. 2010. doi:10.2139/ssrn.1684918

7. Wang Y, Eggleston K, Yu Z, Zhang Q. Contracting with private providers for primary care services: evidence from urban China. Health Econ Rev. 2013;3(1):1. doi:10.1186/2191-1991-3-1

8. Shen Q, Tang L, Feng Y, Tang J. The imbalance between patient needs and the limited competence of top-level health providers in urban China: an empirical study based on a 2008 national household survey. SSRN Electron J. 2010. doi:10.2139/ssrn.1705694

9. Xu Yanli LZ, Hui Y. The reconsideration about Chinese health doorkeeper. Chin Hosp Manage. 2007;27(8):39-41.

10. Liu Biao LX. Thoughts of implementation of the first visit care in urban community health service in China. Chin Gen Pract. 2007;10 (13):1115-1117.

11. NHFPC. Statistic Yearbook of National Health and Family Planning of the People's Republic of China 2013. Pecking Union Medical College Press; 2014.

12. Wu Z, Jian W. Availability and social determinants of community health management service for patients with chronic diseases: an empirical analysis on elderly hypertensive and diabetic patients in an eastern metropolis of China. Family Med Community Health. 2015;3(1):6-14. doi:10.15212/FMCH.2015.0104

13. Yang Y, Yang D. Community health service centers in China, not always trusted by the populations they serve? China Econ Rev. 2009;20(4):620-624. doi:10.1016/j.chieco.2009.04.004

14. Wang H, Wong S, Griffiths S. Development of primary care in China: will community health centres make a difference. Br J Den Pract. 2015.

15. Yang HJ, Huang $X$, Zhou ZH, et al. Determinants of initial utilization of community healthcare services among patients with major non-communicable chronic diseases in South China. PLoS One. 2014;9(12):e116051. doi:10.1371/journal.pone.0116051

16. Wang L. Study on the reform and improvement of the medical device registration system in China. Chin J Med Instrument. 2012;36 (6):426-432.

17. Hu DY. Play the key role in medical reform and take action to lead the "Healthy China 2020". Chin J Cardiol. 2011;39(1):1-2.

18. Chen Z. Launch of the health-care reform plan in China. Lancet. 2009;373(9672):1322-1324.

19. Yuanli L. three-in-one team-based care model. Mod Hosp Manage. 2016;14(4):14-15.

20. Li X, Li Z, Liu C, et al. Evaluation of the three-in-one team-based care model on hierarchical diagnosis and treatment patterns among patients with diabetes: a retrospective cohort study using Xiamen's regional electronic health records. BMC Health Serv Res. 2017;17 (1):779. doi:10.1186/s12913-017-2705-2

21. Yu Y "Three-in-One" model of family doctor contract service in Xiamen. Xiamen Daily. August 26, 2015.

22. Liu W. Hierarchical medical mode of Xiamen. China Hosp CEO. 2015;(18):56-63.

23. Shuyu Yang LC. Chronic diseases first, co-management of doctors of three kinds and reform of hierarchic diagnosis and treatment benefiting masses of people. Mod Hosp Manage. 2016;4(14):2-6+1. 
24. Starfield B. Primary care in Canada: coming or going? HealthcarePapers. 2007;8(2):58-62; discussion 64-57. doi:10.12927/ hcpap.2008.19711

25. Beasley JW, Starfield B, van Weel C, Rosser WW, Haq CL. Global health and primary care research. J Am Board Family Med. 2007;20 (6):518-526. doi:10.3122/jabfm.2007.06.070172

26. Starfield B. Reinventing primary care: lessons from Canada for the United States. Health Affairs. 2010;29(29):1030-1036. doi:10.1377/ hlthaff.2010.0002

27. Li C, Shi L, Huang J, Qian X, Chen Y. Factors associated with utilization of maternal serum screening for Down syndrome in mainland China: a cross-sectional study. BMC Health Serv Res. 2015;16 (1):8. doi:10.1186/s12913-016-1260-6

28. Zhang X, Yu B, He T, Wang P. Status and determinants of health services utilization among elderly migrants in China. Global Health Res Policy. 2018;3(1):8. doi:10.1186/s41256-018-0064-0

29. Golden SD, Earp JAL. Social ecological approaches to individuals and their contexts: twenty years of health education \& behavior health promotion interventions. Health Educ Behav. 2012;39:364-372. doi: $10.1177 / 1090198111418634$

30. Gonder-Frederick LA, Cox DJ, Ritterband LM. Diabetes and behavioral medicine: the second decade. J Consult Clin Psychol. 2002;70 (3):611-625. doi:10.1037/0022-006X.70.3.611

31. Stokols D. Translating social ecological theory into guidelines for community health promotion. Am J Health Promotion. 1996;10 (4):282-298. doi:10.4278/0890-1171-10.4.282

32. McLeroy KR, Bibeau D, Steckler A, Glanz K. An ecological perspective on health promotion programs. Health Educ Behav. 1988;15 (4):351-377.

33. Bronfenbrenner U. The Ecology of Human Development. Harvard university press; 2009.

34. Manning WG, Duan N, Rogers WH. Monte Carlo evidence on the choice between sample selection and two-part models. J Econom. 1987;35(1):59-82. doi:10.1016/0304-4076(87)90081-9

35. Pohlmeier W, Ulrich V. An econometric model of the two-part decisionmaking process in the demand for health care. J Human Resour. 1995;30(2):339-361. doi:10.2307/146123

36. Leung SF, Yu S. On the choice between sample selection and two-part models. J Econom. 1996;72(1):197-229. doi:10.1016/ 0304-4076(94)01720-4

37. Organization WH. 2008-2013 Action Plan for the Global Strategy for the Prevention and Control for Noncommunicable Diseases; 2008.

38. Xiamen Health Care Report. 2014.

39. Sumita M. Communiqué of the national bureau of statistics of People's Republic of China on major figures of the 2010 population census(No.1). China Popul Today. 2011;6(2):21-25.

40. Yu W, Li M, Ye F, Xue C, Zhang L. Patient preference and choice of healthcare providers in Shanghai, China: a cross-sectional study. BMJ Open. 2017;7(10):e016418. doi:10.1136/bmjopen-2017-016418
41. China NH. Analysis Report of National Health Services Survey in China, 2013; 2016.

42. Liu L. Gender Difference of Health Status in the Aging Population of Urban China. Chin Econ. 2008;41(1):58-71. doi:10.2753/CES10971475410103

43. Xuan Yao YZ, Yang H. Analyzing the factors to influence the community health service utilization of residents in Urumqi. Chin Health Serv Manage. 2016;6(6):413-415+432.

44. Tian Shen HC, Chen Z. Survey on utilization of community health services and influential factors for residents in Shanghai. J Shanghai Jiaotong Univ Med Sci. 2010;30(8):944-947+963.

45. Pan X, Dib HH, Wang X, Zhang H. Service utilization in community health centers in China: a comparison analysis with local hospitals. BMC Health Serv Res. 2006;6(1):93. doi:10.1186/1472-6963-6-93

46. Hu S. Discussion on the regulation effect of government in health care. Chin Health Econ. 2006;25(2):10-13.

47. Fernández-Olano C, Hidalgo JDL-T, Cerdá-Díaz R, et al. Factors associated with health care utilization by the elderly in a public health care system. Health Policy. 2006;75(2):0-139. doi:10.1016/j. healthpol.2005.02.005

48. Hernandez-Aceituno A, Perez-Tasigchana RF, Guallar-Castillon P, Lopez-Garcia E, Rodriguez-Artalejo F, Banegas JR. Combined healthy behaviors and healthcare services use in older adults. Am J Prev Med. 2017;53(6):872-881. doi:10.1016/j.amepre.2017.06.023

49. LaVeist T, Pollack K, Thorpe R, Fesahazion R, Gaskin D. Place, not race: disparities dissipate in southwest Baltimore when blacks and whites live under similar conditions. Health Aff. 2011;30 (10):1880-1887. doi:10.1377/hlthaff.2011.0640

50. Zeng Q. Thinking and exploring about Xiamen mode. Health Econ Res. 2016;7:7-9.

51. Guo Qing WX, Xiaohui L. The lorenz curve, gini coefficient and their application study on fairness of resource allocation for community health services. Chin Health Econ. 2006;1(01):50-53.

52. Yanbing Lin SC, Pan H. The analysis of health resources allocation in Xiamen community health services centers. Chin J Health Stat. 2013;30(1):413-415+432.

53. Yun Yao WH, Zuxun L. The equity analysis of human resource allocation of community health services in the cities of Hubei province. Chin Health Econ. 2010;29(4):37-39.

54. Caprihan A, Pearlson GD, Calhoun VD. Application of principal component analysis to distinguish patients with schizophrenia from healthy controls based on fractional anisotropy measurements. Neuroimage. 2008;42(2):675-682. doi:10.1016/j.neuroimage.2008.04.255

55. Wang HHX, Wang JJ, Wong SYS, Wong MCS, Mercer SW, Griffiths SM. The development of urban community health centres for strengthening primary care in China: a systematic literature review. Br Med Bull. 2015;1dv043. doi:10.1093/bmb/ldv043
Patient Preference and Adherence

\section{Publish your work in this journal}

Patient Preference and Adherence is an international, peer-reviewed, open access journal that focuses on the growing importance of patient preference and adherence throughout the therapeutic continuum. Patient satisfaction, acceptability, quality of life, compliance, persistence and their role in developing new therapeutic modalities and compounds to optimize clinical outcomes for existing disease states are major areas of interest for the journal. This journal has been accepted for indexing on PubMed Central. The manuscript management system is completely online and includes a very quick and fair peer-review system, which is all easy to use. Visit http:// www.dovepress.com/testimonials.php to read real quotes from published authors. 